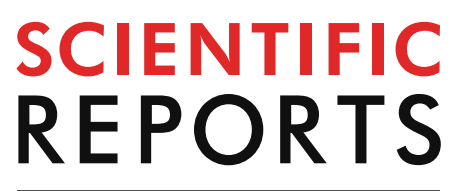

natureresearch

Check for updates

\title{
Effects of different agronomic practices on the selective soil properties and nitrogen leaching of black soil in Northeast China
}

\begin{abstract}
Yujun Wang ${ }^{1,6}$, Hongjun Gao ${ }^{2,6}$, Zhonglei Xie ${ }^{3,4 \bowtie}$, Lifeng Zhang ${ }^{5 \bowtie}$, Xiulan Ma ${ }^{1}$ \& Chang Peng ${ }^{2}$
Considering the large amount and high frequency application of concentrated fertilizer nitrogen in the Black Soil Region of Northeast China, the current laboratory/field simulation study aimed to explore the pollution risk of added nitrogen in black soil to groundwater and identify effective measures to prevent and control soil nitrogen leaching with an undisturbed soil column. The results showed that the saturated nitrogen adsorption capacities increased by $1.7 \%, 7.7 \%$ and $18.5 \%$ in ploughing, impervious agent (starch grafted polyacrylic acid) addition, and corn straw returning treatments, respectively, relative to the control (no-till). When the collection volume of the leaching solution reached the experimental maximum $(4,000 \mathrm{~mL})$, the total amount of nitrogen leaching from the control soil column (i.e., the no-tillage treatment) accounted for more than $50 \%$ of the added nitrogen, indicating a great risk of nitrogen pollution in groundwater. Compared with the no-tillage treatment, the amount of nitrogen leaching from the ploughing treatment increased insignificantly, and the amount of nitrogen leaching in the following spring in the corn straw returning treatment increased by $11.2 \%$. The amount of nitrogen leaching decreased by $12.5 \%$ in the soil sampled in autumn of the second year. The total amount of nitrogen leaching in the soil with impervious agents decreased by $40.1 \%$. Therefore, the permeability-reducing agent could significantly reduce underground water pollution risk posed by nitrogen leaching.
\end{abstract}

The black soil located in the middle of the Northeast Songnen Plain, China, is one of the three famous black soil (Molisol) zones in the world. There is 8.15 million ha of cultivated black soil in Northeast China, which contributes to approximately $20 \%$ of the country's grain production ${ }^{1}$; therefore, black soil serves as an important commodity grain production base in China. Due to the relatively flat terrain of the black soil area, the proportion of non-point source pollutants (nitrogen and phosphorus) entering the water body with surface runoff is relatively low. However, the underground water pollution risk will increase through the vertical migration of nitrogen and phosphorus by leaching. Considering labour costs and planting habits, the farmers in this area mostly adopt a fertilization method called "one-time fertilization" (in which all fertilizers required for the whole growth cycle of crops are applied to the soil at one time when sowing in spring) ${ }^{2}$. This fertilization method will result in a low fertilizer utilization rate (generally no more than $35 \%$ ) and a large amount of chemical fertilizer leaching to the groundwater ${ }^{3}$.

Nitrogen, one of the most important nutrient elements for plant growth, can not only be assimilated by crops but can also evaporate into gaseous forms via mineralization and denitrification and can be fixed with the organic matter of soil ${ }^{4}$. Other forms of nitrogen in soils not involved in the above processes may leach into the underground water ${ }^{5-7}$. In recent years, the leaching loss of soil nitrogen in cultivated land has become one of the major contributors to water pollution in many areas of $\mathrm{China}^{8}$, and the nitrogen pollution in water is closely related to land-use patterns and irregular events such as rainfall and soil disturbance; moreover, the leaching

\footnotetext{
${ }^{1}$ College of Resources and Environment, Jilin Agricultural University, Changchun 130118, Jilin, China. ${ }^{2}$ Institute of Agricultural Environment and Resources Research, Jilin Academy of Agriculture Sciences, Changchun 130033, Jilin, China. ${ }^{3}$ College of Plant Science, Jilin University, Changchun 130062, Jilin, China. ${ }^{4}$ College of Construction Engineering, Changchun Sci-Tech University, Changchun 130600, Jilin, China. ${ }^{5}$ College of Tourism and Geographic Sciences, Jilin Normal University, Siping 136099, Jilin, China. ${ }^{6}$ These authors contributed equally: Yujun Wang and Hongjun Gao. ${ }^{\circledR}$ email: xiezl@jlu.edu.cn; 934360557@qq.com
} 


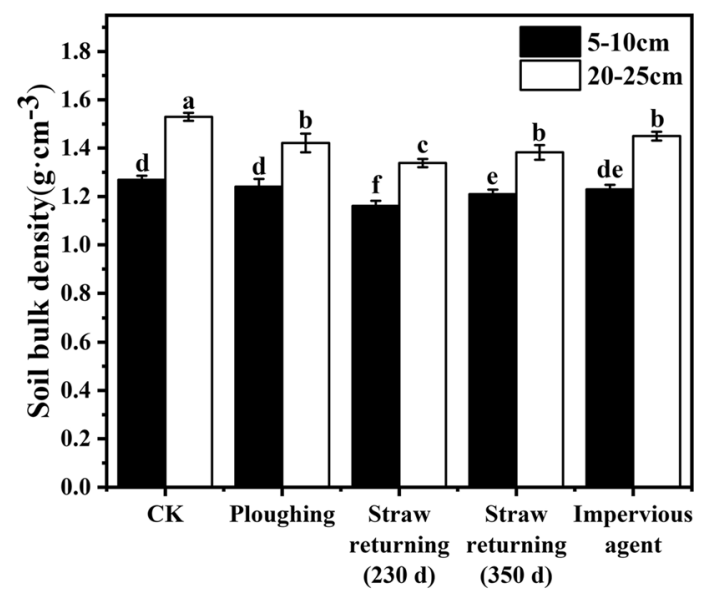

Figure 1. Effect of different agronomic practices on soil bulk density.

loss of soil nitrogen is difficult to control effectively ${ }^{9-12}$. Currently, the risk of nonpoint source pollution in the black soil region of Northeast China is increasing because the loss of nitrogen in black soil increased by $92 \%$ during 20 years $^{1,13,14}$. Consequently, effective measures should be taken to control soil nitrogen leaching under the premise of maintaining the soil fertility of the black soil area in Northeast China ${ }^{15}$. An effective way to control nitrogen leaching in irrigated farming is to optimize irrigation management because controlling the irrigation amount and frequency will effectively limit the amount of water moving out of the active rooting area, thus reducing nitrogen leaching loss ${ }^{16,17}$. However, in the black soil area, almost all farmland is rain-fed farming ${ }^{18}$, and optimized irrigation is not an option for controlling nitrogen leaching in the region.

In the black soil area of Northeast China, the degree of agricultural mechanization is increasing, and the no tillage method is increasing each year. The use of agricultural machinery and the no-tillage mode can lead to an increase in the degree of soil compaction; hence, some farmers are ploughing the land before sowing to soften the topsoil. After ploughing, the soil roughness, porosity and water storage capacity increase ${ }^{18}$, which can significantly inhibit surface runoff, and the sediment yield after ploughing decreases by more than $40 \%$ compared with no tillage ${ }^{19}$. The soil is loose, and the bulk density decreases after ploughing; however, whether it aggravates the vertical transport of nitrogen and increases the risk of groundwater pollution remain unclear. In the black soil area of Northeast China, surplus crop straw (mainly corn) in the field has become popular in recent years. The straw remaining in the field can lead to a decrease in soil bulk density and an increase in soil organic matter ${ }^{20}$. In addition, impervious agents added to soil have a certain inhibitory effect on nitrogen leaching ${ }^{21}$. Polyacrylic acid, an impervious agent, can keep water in soil because of its hydrophilic carboxyl group in its molecular structure; however, the cost of adding polyacrylic acid to the soil is relatively high, which limits its application in agriculture. Starch contains a large number of hydrophilic hydroxyl groups and has a strong water retention capacity. Grafting starch onto polyacrylic acid can greatly reduce the cost of using polyacrylic acid. Therefore, polyacrylic acid-grafted starch has been used as a soil water retaining agent ${ }^{22}$. The dissolving speed of starchgrafted polyacrylic acid as an impervious agent in the soil is faster than that of expansion and adhesion. Under the condition of sufficient soil moisture, the impervious agent in the surface layer dissolves and then penetrates into the soil, gradually expands and binds with other particles, blocking the space between the soil particles, thus playing a role of being impervious ${ }^{23}$. Consequently, the impervious agent can be directly applied to the $5-10 \mathrm{~cm}$ layer of soil to achieve an impervious effect in deep soil under high soil moisture content conditions ${ }^{24}$. Currently, the effect of straw remaining and impervious agent addition on nitrogen migration in the soil is lacking. Accordingly, the aims of this research were to (1) study the effects of ploughing, straw deep returning and adding an impervious agent on the physical and chemical properties of soil; (2) explore the adsorption capacity of soil to nitrogen; and (3) investigate the leaching characteristics of nitrogen in undisturbed soil columns.

\section{Results and discussion}

Effects of different agronomic practices on soil bulk density and organic matter content. Soil bulk density can be used to evaluate the compactness and porosity of soil particles. Generally, the lower the soil bulk density is, the higher the porosity is, and the stronger the water permeability is ${ }^{25}$; consequently, the nitrogen leaching in the soil will be higher, and there will be a higher risk of groundwater pollution. The effect of different agronomic practices on soil bulk density is shown in Fig. 1. The bulk density of the $5-10 \mathrm{~cm}$ layer soil for CK (notillage control) was $1.27 \mathrm{~g} \mathrm{~cm}^{-3}$, which was higher than the $1.21 \mathrm{~g} \mathrm{~cm}^{-3}$ in the CK soil from the previous year. This result was mainly related to compaction from rainfall and mechanical operation. The subsoil bulk density (20$25 \mathrm{~cm}$ ) of the no-till CK was $1.53 \mathrm{~g} \mathrm{~cm}^{-3}$, which was $16.6 \%$ higher than that of the topsoil $(5-10 \mathrm{~cm})$, which was mainly attributed to less disturbance in the subsoil than in the topsoil. Because of the disturbances of ploughing, straw returning and adding an impervious agent to the soil, the soil bulk density of all the above treatments decreased compared with that of the no-tillage CK. There was no significant difference between the ploughing and impervious agent addition treatments; however, straw returning significantly decreased the soil bulk density compared with that of no straw retuning (the simple tillage treatment). The soil bulk densities increased obvi- 


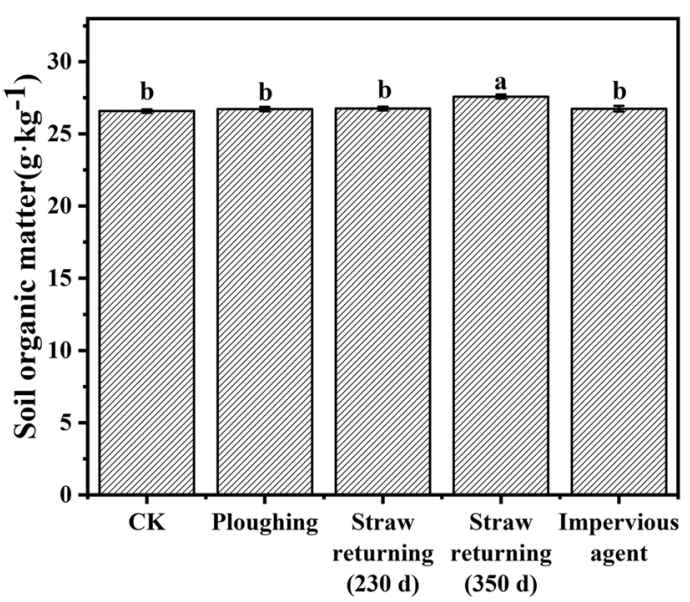

Figure 2. Effect of different agronomic practices on soil organic matter content.

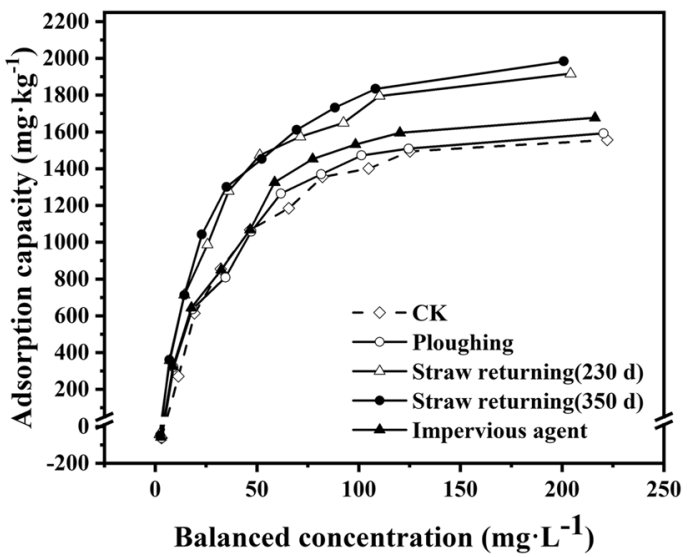

Figure 3. Adsorption isotherm curve of nitrogen in soils treated with different agronomic practices.

ously with increasing time of crop return (230 days versus 350 days), which reflected differences in the extent of residue decomposition in soils, which decayed slowly in the first 230 days coupled with low temperature and had lower decomposition during the autumn, winter and spring compared with the quick decomposition period from 230 to 350 days (summer season) when the soil was wet and warm in the study area. The wetter and warmer soil conditions during the period from 230 to 350 days were associated with stronger microbial activity, which facilitated the rapid decomposition of corn straw, resulting in an increase in soil compactness and bulk density.

Organic matter can improve soil structure, effectively hold water and crop nutrients, and effectively reduce leaching loss of nitrogen ${ }^{25}$. Figure 2 shows the effects of different agronomic practices on the contents of soil organic matter. Non-decomposed corn straw was visible in the soils after 230 days of corn straw returning and should be removed before organic matter determination from the soil samples. However, non-decomposed corn straw was invisible from the soil after 350 days of corn straw returning. It is believed that a portion of corn straw in the soil was converted into the soil organic matter pool, resulting in soil organic matter that was $3.8 \%$ higher after 350 days of straw returning than that in the control. Although much straw did not convert into soil organic matter after 230 days of straw returning, this kind of organic material probably had an impact on the migration of soluble substances in the soil ${ }^{26}$.

Adsorption characteristics of nitrogen in cultivated soil treated with different agronomic practices. Figure 3 shows the adsorption isotherm curves of nitrogen in black soil with different agronomic practices under a constant temperature of $25^{\circ} \mathrm{C}$. The initial adsorption capacity of each treatment without exogenous nitrogen addition was negative, which was mainly caused by nitrogen in the soil dissolved into the solution ${ }^{22}$. When the concentration of exogenous nitrogen increased, the initial dissolved nitrogen in the soil could be ignored. In the low range of nitrogen concentrations $\left(<125 \mathrm{mg} \mathrm{L}^{-1}\right)$, the adsorbed nitrogen in the soil increased sharply with increasing nitrogen concentration in the solution. When the equilibrium concentration of nitrogen reached a certain upper limit $\left(>125 \mathrm{mg} \mathrm{L}^{-1}\right)$, the adsorbed amount of nitrogen in the soil did not increase with an 

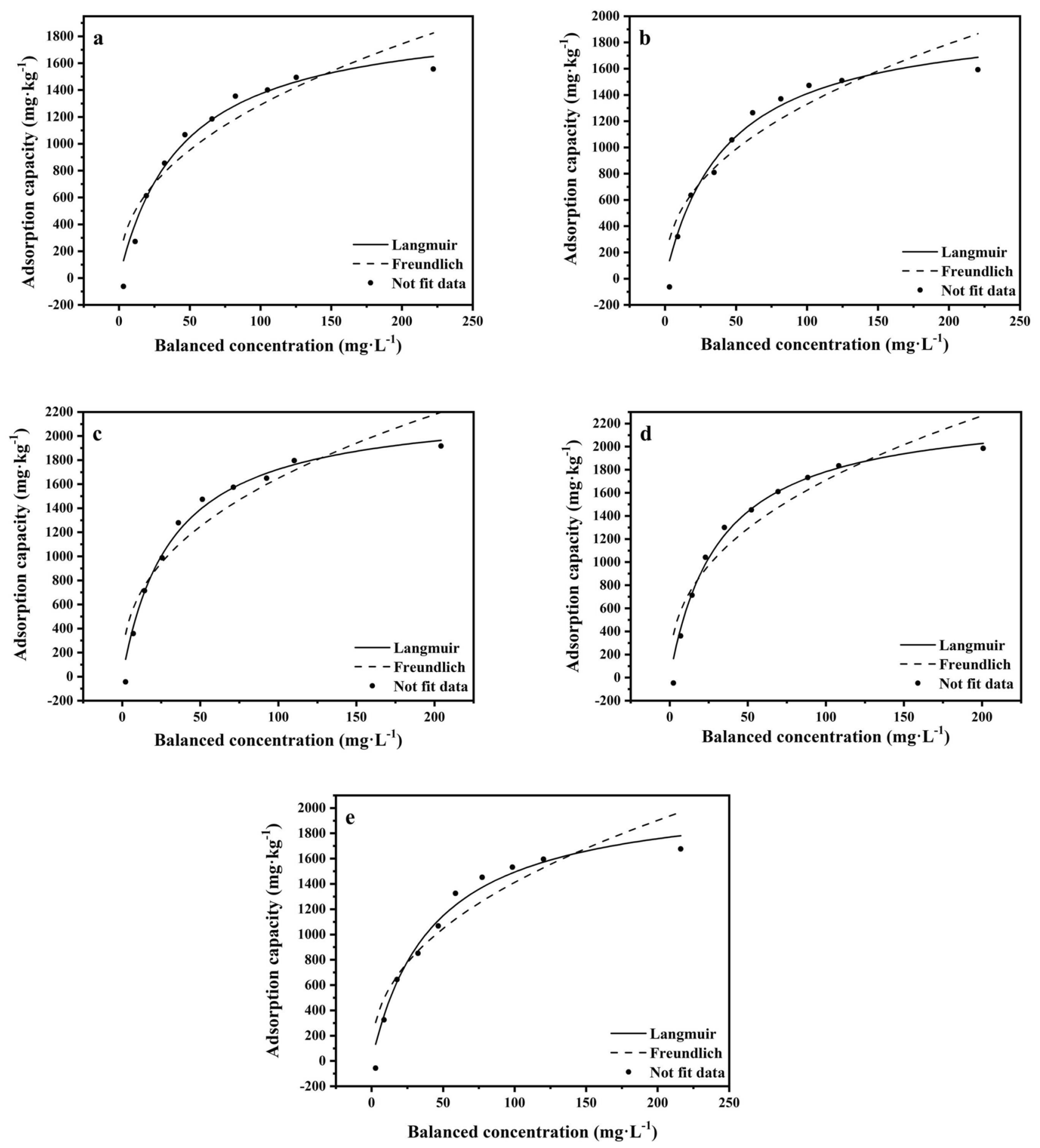

Figure 4. Fitting curve of nitrogen adsorption isotherm in different soils. (a) CK, (b) ploughing, (c) straw returning (230 days), (d) Straw returning (350 days), (e) impervious agent.

increase in the nitrogen concentration of the solution, which indicated that the adsorption capacity of nitrogen in black soil reached equilibrium.

The adsorption characteristics of nitrogen in the soils were fitted with different models under different agronomic practices. Fitting could be done using the linear Henry equation in the lower nitrogen balance concentration and with the Freundlich or Langmuir equations in the higher nitrogen balance concentration ${ }^{27}$. Figure 4 is the curve of the Freundlich and Langmuir equations of nitrogen adsorption in the soils. The Langmuir equation deviates less from reality; further, the fitting results in Table 1 are consistent with those in Fig. 4.

According to the Langmuir equation, the saturated adsorption capacity $\left(\mathrm{Q}_{e}\right)$ of nitrogen in the soils increased by $1.7 \%, 14.5 \%, 18.5 \%$ and $7.7 \%$ for the soils treated with ploughing, straw returning for 230 days and 350 days, 


\begin{tabular}{|l|l|l|l|}
\hline \multirow{2}{*}{ Treatment } & \multicolumn{3}{|l|}{ Langmuir } \\
\cline { 2 - 4 } & $\boldsymbol{k}_{\boldsymbol{L}}$ & $\mathbf{Q}_{\boldsymbol{e}}$ & $\boldsymbol{r}$ \\
\hline CK & 0.02247 & 1981.3 & $0.9848^{* *}$ \\
\hline Ploughing & 0.02328 & 2015.1 & $0.9857^{\star *}$ \\
\hline Straw returning (230 days) & 0.03167 & $2,267.9$ & $0.9920^{* *}$ \\
\hline Straw returning (350 days) & 0.03155 & $2,347.6$ & $0.9918^{* *}$ \\
\hline Impervious agent & 0.02330 & $2,134.6$ & $0.9868^{\star *}$ \\
\hline
\end{tabular}

Table 1. Fitting results of adsorption thermodynamics equation of nitrogen in tested soils. ${ }^{\star *}$ indicates an extremely significant correlation $(p \leq 0.001)$

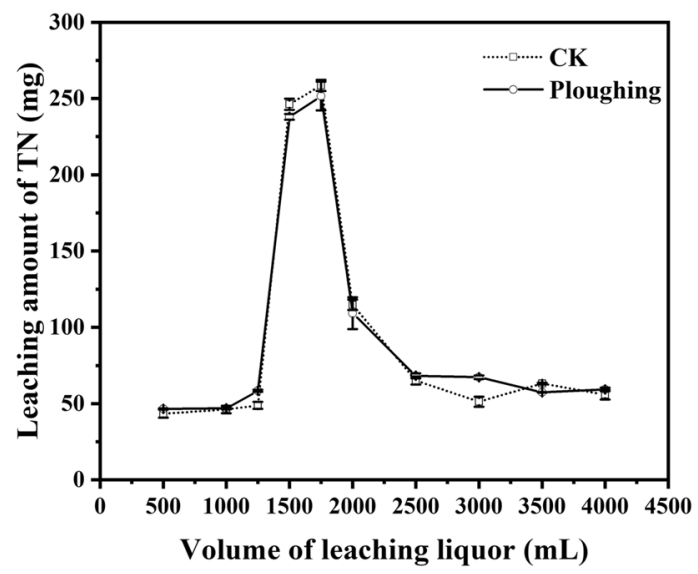

Figure 5. Effect of ploughing treatment on nitrogen leaching in the soil.

and addition of an impervious agent, respectively, compared with that of the no-tillage treatment. The nitrogen adsorption capacity in ploughed soil increased insignificantly, which may be related to the fact that the plough mainly changed the soil physical properties (e.g., bulk density and permeability) but had no significant effect on the chemical composition and soil colloidal properties. Nevertheless, there was a slight increase in the adsorption capacity of nitrogen in the soil treated with impermeable agents. The result may be because certain functional groups, such as hydroxyl groups, carboxyl groups and starch and acrylic acid originating from the impermeable agent, enable the formation of a network structure with nitrogen and contribute to the adsorption of nitrogen ${ }^{28}$. The adsorption capacity of nitrogen increased by $14.5 \%$ in the corn straw treatment (230 days), which may be because the straw in the soil just started to decay and had not been converted into soil organic matter ${ }^{28}$. Moreover, the straw that had decayed partially had a large specific surface area, which could contribute to the adsorption of nitrogen in soil. The adsorption capacity of nitrogen increased by $18.5 \% 350$ days after straw was returned to the field, indicating that the newly formed organic substance from straw had a great adsorption capacity for nitrogen. Furthermore, dissolved soil organic matter can enhance the adsorption of nitrogen in soils through ion exchange, adsorption and chelation ${ }^{29}$.

The adsorption of nitrogen in soils is affected directly and indirectly by soil organic matter ${ }^{30}$. The direct effect is that soil organic matter forms a relatively stable particle complex with nitrogen through physical and chemical adsorption or forms a more stable chelate with dissolved nitrogen through complexation ${ }^{31}$, and the indirect effect is by adjusting the physical and chemical properties of soil, such as $\mathrm{pH}$ and Eh, or by making nitrogen reach the soil surface or enter the soil interior easily, which results in an increase in the adsorption of nitrogen in soils. Therefore, the application of organic substances can increase the nitrogen holding capacity of soil and mitigate the risk of groundwater pollution by reducing the leaching loss of nitrogen in soils.

Leaching characteristics of nitrogen in soil under different agronomic practices. The same amount of leaching water $(4,000 \mathrm{~mL})$ was collected from each leaching column with a total of 10 sampling segments (subsamples) as described in the Materials and Methods section. The majority of leached nitrogen was recovered in the 4 th and 5 th samples after $1,250 \mathrm{~mL}$ of leaching water passed through the column, with the same trend for all treatments (Figs. 5, 6,7). Another similar feature for all treatments was that only a small amount of nitrogen $(<150 \mathrm{mg}$, approximately $15 \%$ of the total nitrogen addition) was recovered in the first three leachate samples $(1,250 \mathrm{~mL})$, and it was certain that the nitrogen was not from added urea but from residual soil nitrogen.

CK. A total amount of $993.5 \mathrm{mg}$ nitrogen was collected from this treatment, which was more than $50 \%$ of the added nitrogen. More than $50 \%$ of the leached nitrogen occurred in the $4^{\text {th }}$ sampling segment $(1,250-1,750 \mathrm{~mL})$. Although nitrogen in soil is highly soluble, the amount of nitrogen leaching in the soils in this experiment was 


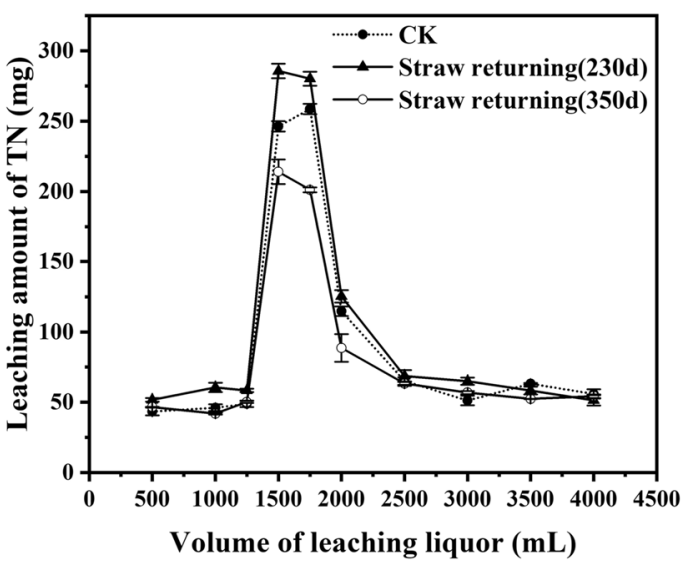

Figure 6. Effect of straw returning on soil nitrogen leaching.

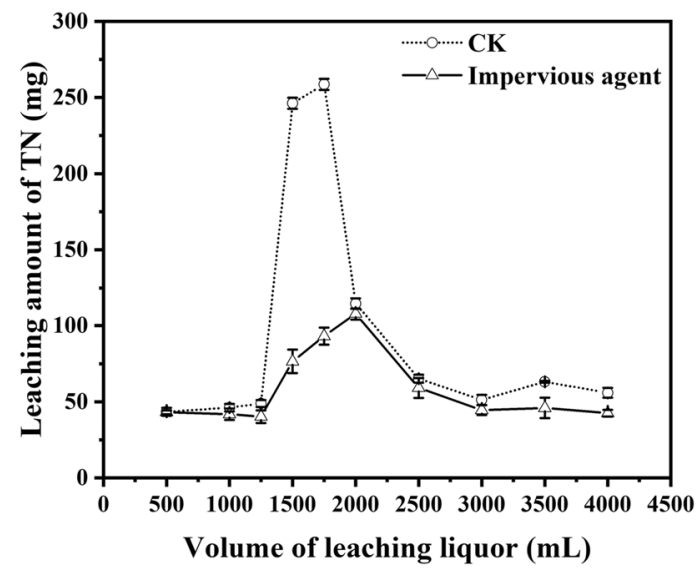

Figure 7. Influence of adding the impervious agent on nitrogen leaching.

not particularly high, and nearly $50 \%$ of nitrogen remained in the soil. The results were similar to Chen's study on nitrogen transport in black soil in this area ${ }^{31}$, and this similarity may reflect the low amount of residual nitrogen in the soil column after pre-leaching and the strong adsorption capacity of soil colloids for nitrogen ${ }^{32}$.

Ploughing treatment without corn straw return. Without corn straw return, there was no difference in nitrogen leaching between the ploughing and no-tillage treatments (Fig. 5) ( $t$-test, $\mathrm{P}>0.05$ ), indicating that ploughing (top $10 \mathrm{~cm}$ ) had no significant impact on the performance of nitrogen leaching and would not increase the risk of nitrogen pollution to groundwater. Although the soil bulk density decreased significantly and the soil structure was loose after ploughing, which was conducive to nitrogen leaching ${ }^{33}$, proper ploughing can destroy the large pore space of the arable soil, inhibit the generation of soil preferential flow, block the migration of nitrogen to groundwater, and reduce nitrogen leaching. These confounding effects led to insignificant changes in the characteristics of nitrogen leaching in ploughed soils compared with no-tillage soils.

Ploughing treatment with straw returning. Figure 6 shows the leaching results from two sets of soil columns. One set of soil was collected after 230 days of corn straw addition, and another was collected after 350 days of straw addition. There was more nitrogen leaching $(1,105.2 \mathrm{mg} \mathrm{N})$ in the former and less nitrogen leaching $(869.6 \mathrm{mg} \mathrm{N})$ in the latter compared with that in the control $(993 \mathrm{mg} \mathrm{N})$. This difference was probably due to the difference in corn straw status in the soil. For the soil column collected after 230 days of straw return, the straw was decomposed partially under the conditions of the low temperature and soil moisture in early spring ${ }^{3}$. Nondecomposed straw also resulted in a lower soil bulk density, higher soil porosity, higher permeability and more nitrogen leaching out of the column compared with that of the soil column collected after 350 days of corn straw returning, in which the corn straw had experienced more complete decomposition during the wet and warm summer. More humified organic matter from decomposed straw had a high cation exchange capacity relative to un-humified organic substances. It was confirmed that decomposed straw was more beneficial to prevent the loss of nitrogen in black soil. If the straw was returned to the field after the autumn harvest, excessive fertilization should be prohibited in the sowing period to reduce the loss of nitrogen due to the incomplete decomposition 


\begin{tabular}{|l|l|l|}
\hline Treatment & Pre leaching stage $\left(\mathrm{mL} \mathrm{min}^{-1}\right)$ & Leaching stage after nitrogen application $\left(\mathrm{mL} \mathrm{min}^{-1}\right)$ \\
\hline CK & $6.6 \pm 0.2 \mathrm{a}$ & $6.5 \pm 0.2 \mathrm{a}$ \\
\hline Impervious agent & $6.5 \pm 0.1 \mathrm{a}$ & $3.8 \pm 0.1 \mathrm{~b}$ \\
\hline
\end{tabular}

Table 2. The effect of adding impervious agent on the rate of drenching solution.

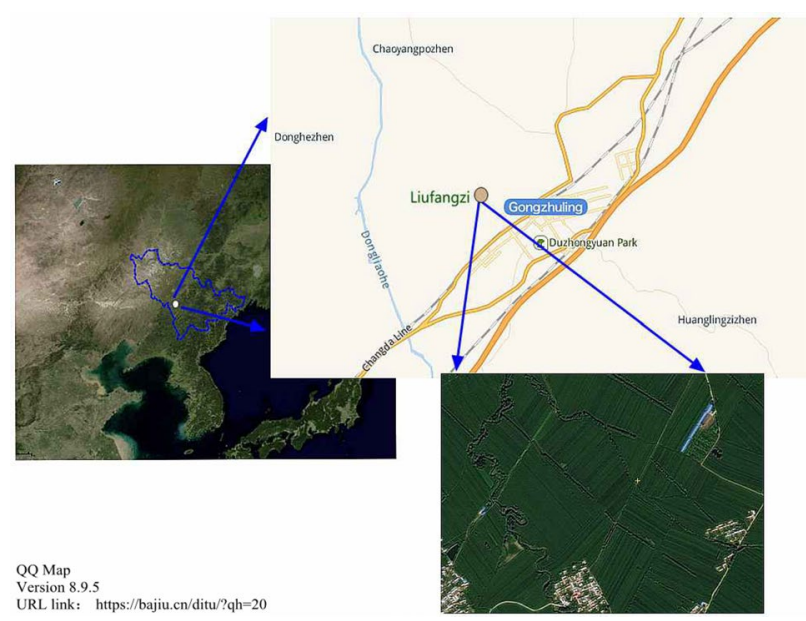

Figure 8. Location of study area (Liufangzi Village, Gongzhuling City, Jilin Province).

of straw and the strong leaching of soil nitrogen ${ }^{34}$. Of course, fertilization methods also had a great influence on nitrogen leaching solution; for example, the "one-time fertilization" approach, which has been widely used in the studied area, was a very environmentally unfriendly way of fertilization and should be prohibited ${ }^{35}$.

Treatment of adding impervious agents. The effect of adding impervious agents on the rate of drenching solution is shown in Table 2. The results of the pre-leaching experiment showed that there was no significant difference in the rate of water infiltration between the treatments with and without impervious agents, which may be related to the lower soil moisture content, the less obvious expansion of the impervious agent molecules and the lower blocking effect on the soil voids. When the leaching experiment started and the collection volume of the leaching solution reached $4,000 \mathrm{~mL}$ without limiting the outflow, the average flow rate of the leaching solution was $3.8 \mathrm{~mL} \mathrm{~min}{ }^{-1}$ for the impervious agent addition treatment, which was significantly lower than that of the control treatment $\left(6.5 \mathrm{~mL} \mathrm{~min}^{-1}\right)$. This result was mainly related to the strong blocking effect of the expansion of impervious agents in the soil void after a long period of water immersion.

Figure 7 shows that the peak of nitrogen leaching was delayed with impervious agent treatment relative to the control. The peak and total leaching amounts of nitrogen were $107.8 \mathrm{mg}$ and $594.7 \mathrm{mg}$, respectively, which were significantly lower than that of the control (250 mg nitrogen for peak and $993 \mathrm{mg}$ nitrogen for total). Therefore, the effect of impervious agents on preventing soil nitrogen leaching was obvious, and starch-grafted polyacrylic acid, as an impervious agent, can effectively inhibit the infiltration of soil water and the leaching loss of soil nitrogen.

\section{Conclusions}

Compared with the control (no tillage), tillage had no significant effect on the soil organic matter content, nitrogen adsorption capacity or leaching amount in black soil. The soil organic matter content and nitrogen adsorption capacity of the soil were significantly increased for the straw returning treatment. Due to the influence of straw decay degree, the leaching amount of soil nitrogen increased by $11.2 \%$ when straw was returned to the field for 230 days and decreased by $12.5 \%$ when straw was returned to the field for 350 days. The addition of an impervious agent (starch grafted polyacrylic acid) did not increase the content of soil organic matter but could enhance the adsorption capacity of nitrogen and significantly reduce the leaching loss of nitrogen in black soil.

\section{Materials and methods}

General situation of the research area. The research area was conducted at Liufangzi village, Gong-

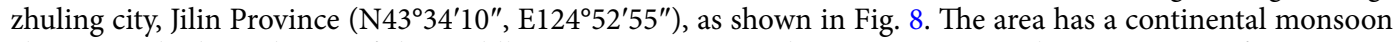
climate in the humid area of the middle temperate zone, with an average annual precipitation of $594.8 \mathrm{~mm}$, which is mainly concentrated in June and August. The average annual temperature is $5.6^{\circ} \mathrm{C}$, and the daily average temperature drops to $0^{\circ} \mathrm{C}$ in November of each year, with a freezing period of up to five months. Corn is one of the main commodity crops in the area, with a sowing date in early May and a harvest date in early October. 
a

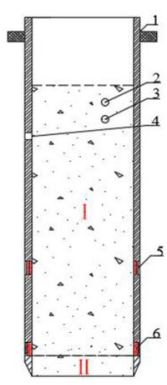

b

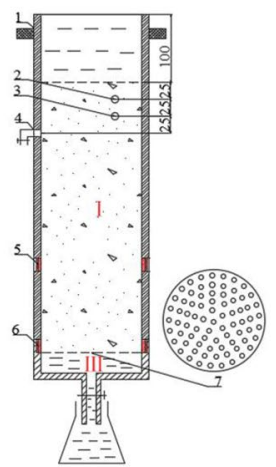

C

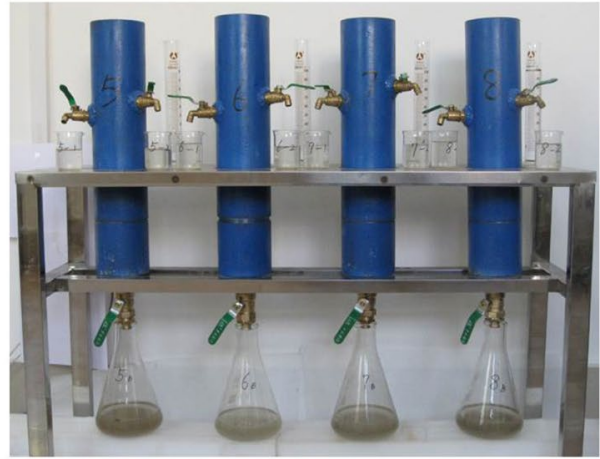

Figure 9. Schematic diagram of simulated leaching device of undisturbed soil column. (a) Soil extraction; (b) leaching; (c) physical map of leaching in undisturbed soil column. 1: Handle; 2.3.4: guide port; 5.6: screw port; 7: punching plate. I main body of leaching column; II soil cutter; III leaching solution collector.

The soil of the site is a silty loam black soil, which had been planted with monoculture corn with no tillage for 5 years. On October 5, 2018 (after the autumn harvest), a flat field was selected to set up the experiment. Soil samples were collected using the zigzag sampling method, and selective physical and chemical properties of soil were determined, including $\mathrm{pH}$ (5.48), organic matter $\left(26.4 \mathrm{~g} \mathrm{~kg}^{-1}\right)$, clay $(29.12 \%)$, and soil bulk density $\left(1.21 \mathrm{~g} \mathrm{~cm}^{-3}\right.$ in $5-10 \mathrm{~cm}$ and $1.53 \mathrm{~g} \mathrm{~cm}^{-3}$ in $\left.20-25 \mathrm{~cm}\right)$.

Reagents and instruments. Reagents. The main raw material of the added impervious agent was corn starch and acrylic compound, which was entrusted to Jilin Yida Chemical Co., Ltd. The added urea was an analytical reagent, and the reagents used for analysis included $\mathrm{H}_{2} \mathrm{SO}_{4}, \mathrm{H}_{3} \mathrm{PO}_{4}, \mathrm{NaOH}, \mathrm{NH}_{4} \mathrm{OH}, \mathrm{NH}_{4} \mathrm{Cl}_{2} \mathrm{~K}_{2} \mathrm{~S}_{2} \mathrm{O}_{8}$, $\mathrm{Na}_{2} \mathrm{~B}_{4} \mathrm{O}_{7}, \mathrm{KNO}_{3}, \mathrm{KNO}_{2}, \mathrm{~K}_{2} \mathrm{Cr}_{2} \mathrm{O}_{7}, \mathrm{FeSO}_{4}$, sulfonamide, and naphthalene ethylenediamine hydrochloride; these were all analytical reagents provided by Beijing Chemical Plant.

Instruments laboratory-built soil leaching column; continuous flow injection analyser (SKALAR SA++, Netherlands).

Test plot setup and agronomic practices. The experimental plots were maintained in the field consisting of (1) CK (no-tillage control treatment, with corn straw removed and soil left under no-till management); (2) ploughing treatment (corn straw was removed and then mouldboard ploughed to a $30 \mathrm{~cm} \mathrm{depth);} \mathrm{(3)} \mathrm{straw}$ returning treatment (corn straw (25.32\% moist) was incorporated into the soil on October 5, 2018 (after autumn harvest), with an application amount of $1.25 \mathrm{~kg} \mathrm{~m}^{-2}$. Briefly, corn straw was chopped into small pieces $(0.5 \mathrm{~cm}$ length), evenly placed on the soil surface, and then incorporated into the soil with ploughing (the depth of $30 \mathrm{~cm}$ )); and (4) impervious agent addition treatment (the impervious agent mentioned previously evenly laid on the soil surface at the amount of $15 \mathrm{~g} \mathrm{~m}^{-2}$ and then incorporated into the $0-30 \mathrm{~cm}$ soil by mouldboard ploughing). The abovementioned field operations were conducted after corn harvest in the fall of 2018 with a testing area of $10 \mathrm{~m} \times 50 \mathrm{~m}$ for each plot and three replicates for each treatment. In the following spring (2019), grain corn was planted in all treatment plots with a planting density of 65,000 plants $\mathrm{ha}^{-1}$. All plots were managed in the same way with a one-time fertilization application of $200-90-90 \mathrm{~kg}(\mathrm{~N}-\mathrm{P}-\mathrm{K}) \mathrm{ha}^{-1}$ and $2,4-\mathrm{d}$ spray as weed control.

For all the above treatments (including the control treatment), undisturbed soils $(0-30 \mathrm{~cm}$ layer) were collected with an undisturbed soil column (refer to Fig. 9) for the leaching experiment on September 25, 2019 (before autumn harvest, after 350 days of straw returning to the field); soil samples of $0-15 \mathrm{~cm}$ were collected for determination of soil organic matter and adsorption experiment of nitrogen in the soil; and soil samples of 5-10 cm and 20-25 cm layers were collected for determination of soil bulk density. In addition, for the straw returning treatment, one sampling was added on May 25, 2019 (one month after sowing, 230 days after straw returning), for the determination of soil organic matter content and soil bulk density, nitrogen adsorption and leaching experiment in soil.

The soil samples used for soil organic matter determination and nitrogen absorption testing were air dried, sieved through a $2-\mathrm{mm}$ sieve and visible plant debris and stones were removed, and then stored.

Experiment of nitrogen adsorption in soil. Ten parts of the soil samples (air-dried, $<2 \mathrm{~mm}$ and $1.00 \mathrm{~g}$ per part) were weighed into a triangular flask (numbered 1 to 10 ), and then $20.00 \mathrm{~mL}$ of urea solution with different nitrogen concentrations of $0,25,50,75,100,125,150,175,200$, and $300 \mathrm{mg} \mathrm{L}^{-1}$ was added to each flask numbered 1 to 10 , respectively. The flasks were placed in an incubator with oscillator shaking for $4 \mathrm{~h}$ at a constant temperature of $25 \pm 1^{\circ} \mathrm{C}$, and then the supernatant was collected to determine the total nitrogen in the solution. This test was performed with 3 replicates for each treatment. 
Nitrogen leaching test with undisturbed soil column. The structure of the leaching column. The leaching column was made of stainless with an inner diameter of $10 \mathrm{~cm}$ and three parts: part I (the main body of the leaching column), part II (the soil cutter, used for soil core collection) and part III (the collector of leaching solution, used for leachate collection) (see Fig. 9). The height of the leaching column was $40 \mathrm{~cm}$, with the top $10 \mathrm{~cm}$ empty for holding leaching solution and the bottom $30 \mathrm{~cm}$ was filled with undisturbed soil.

Collection of undisturbed soil columns. The bottom of part I was connected with part II, and the undisturbed soil column was collected by pressing the handles vertically. When the soil surface of the soil column was $10 \mathrm{~cm}$ away from the upper end of the column, the sampling was finished. To reduce the soil disturbance and resistance during the sampling process, the soil surrounding the targeted soil column was first removed carefully with a spade (manually) and the diameter of the soil column was left slightly larger than the inner diameter of the leaching column, watered evenly and slowly; then, the leaching column was carefully placed on top of the soil column and gently pressed down to the required depth.

Leaching method of nitrogen in undisturbed soil column.

(1) Pre-leaching and exogenous nitrogen addition The soil in the collected undisturbed soil column of part II was scraped off, part II was removed, and part III was connected to part I (see Fig. 9b). The flow control valve at the three diversion ports was connected at the upper end of component I to simulate the surface runoff under the field conditions, and the leaching speed was controlled through the flow valve at the lower end (part III). Before the nitrogen leaching experiment, the soil column was pre-leached with 3,000 $\mathrm{mL}$ deionized water to remove soil residual nitrogen. The eluent was discarded, and the soil column was placed for $48 \mathrm{~h}$ before the start of the leaching experiment.

The top $1 \mathrm{~cm}$ of undisturbed soil was collected as the covering soil, and then $2 \mathrm{~cm}$ of additional undisturbed soil was taken and mixed thoroughly with $4.0 \mathrm{~g}$ of urea. The soil-urea mixture was installed back into the leaching column, covered again with the covering soil, and then placed for $4 \mathrm{~h}$ before the leaching test.

(2) Leachate collection The leaching test was conducted by adding deionized water to the soil leaching column. The leaching process was carried out continuously until the projected volume of leachate was achieved. The total volume of projected leachate collection was $4,000 \mathrm{~mL}$, roughly equivalent to the average annual precipitation $(510 \mathrm{~mm})$ in the study area. In total, 10 leachate samples were collected from each column, and the sample volumes varied from $250 \mathrm{~mL}$ each for the $3 \mathrm{rd}$ to 6 th samples and $500 \mathrm{~mL}$ each for the rest of the samples. To eliminate the influence of temperature on the leaching process, the leaching test was carried out in a constant temperature chamber at $25 \pm 1^{\circ} \mathrm{C}$.

Analysis method. Soil bulk density was determined with the ring knife method. Soil organic matter and total nitrogen contents were analysed using the potassium dichromate volumetric method and N-(1-naphthyl) ethylene diamine dihydrochloride spectrophotometry, respectively ${ }^{36}$.

Data processing methods. Adsorption capacity. The amounts of nitrogen adsorbed by the soils were determined using the following equation (Eq. 1):

$$
Q=\left(c_{0}-c_{e}\right) V / m
$$

where $Q\left(\mathrm{mg} \mathrm{L}^{-1}\right)$ is the adsorption capacity, $c_{0}\left(\mathrm{mg} \mathrm{L}^{-1}\right)$ denotes the initial solution concentration of the adsorption test, $c_{e}\left(\mathrm{mg} \mathrm{L}^{-1}\right)$ represents the concentrations of the adsorption equilibrium solution, and " $m$ " refers to the soil quantity $(\mathrm{g})^{27}$.

Two isothermal models were used to calculate the nitrogen adsorption capacity (Eqs. 2 and 3):

$$
\begin{gathered}
\text { Langmuir equation : } Q=k_{L} Q_{e} c_{e} /\left(1+k_{L} c_{e}\right) \\
\text { Freundlich equation : } Q=k_{F} c_{e}^{1 / n}
\end{gathered}
$$

where $Q\left(\mathrm{mg} \mathrm{L}^{-1}\right)$ is the adsorption capacity, $c_{e}\left(\mathrm{mg} \mathrm{L}^{-1}\right)$ represents the concentration of the adsorption equilibrium solution, $Q_{e}\left(\mathrm{mg} \mathrm{L}^{-1}\right)$ refers to the saturated adsorption, and $k_{L}, k_{F}$, and $n$ are constants related to adsorption capacity ${ }^{27}$.

Microsoft Excel 2010 was used for data processing and statistical analysis, and Origin 8.5 software was used to fit the data. T-test was used to test the difference between the two groups.

Received: 20 January 2020; Accepted: 17 August 2020

Published online: 10 September 2020

\section{References}

1. Gu, Z. et al. Quantitative assessment of soil productivity and predicted impacts of water erosion in the black soil region of northeastern China. Sci. Total Environ. 637, 706-716. https://doi.org/10.1016/j.scitotenv.2018.05.061 (2018).

2. Meng, H.-Q. et al. Soil $\mathrm{pH}$ dynamics and nitrogen transformations under long-term chemical fertilization in four typical Chinese croplands. J. Integr. Agric. 12, 2092-2102. https://doi.org/10.1016/S2095-3119(13)60398-6 (2013). 
3. Biddau, R. et al. Source and fate of nitrate in contaminated groundwater systems: Assessing spatial and temporal variations by hydrogeochemistry and multiple stable isotope tools. Sci. Total Environ. 647, 1121-1136. https://doi.org/10.1016/j.scito tenv.2018.08.007 (2019).

4. Petrovic, A. M. The fate of nitrogenous fertilizers applied to turfgrass. J. Environ. Qual. 19, 1-14. https://doi.org/10.2134/jeq19 90.00472425001900010001x (1990).

5. Wang, F. \& Bettany, J. Organic and inorganic nitrogen leaching from incubated soils subjected to freeze-thaw and flooding conditions. Can. J. Soil Sci. 74, 201-206 (1994).

6. Singleton, P., McLay, C. A. \& Barkle, G. Nitrogen leaching from soil lysimeters irrigated with dairy shed effluent and having managed drainage. Soil Res. 39, 385-396 (2001).

7. Hood, E. W., Williams, M. W. \& Caine, N. Landscape controls on organic and inorganic nitrogen leaching across an alpine/subalpine ecotone, Green Lakes Valley, Colorado Front Range. Ecosystems 6, 31-45. https://doi.org/10.1007/s10021-002-0175-8 (2003).

8. Liu, W. et al. Water resources conservation and nitrogen pollution reduction under global food trade and agricultural intensification. Sci. Total Environ. 633, 1591-1601. https://doi.org/10.1016/j.scitotenv.2018.03.306 (2018).

9. Wang, Y. C. et al. Estimating soil nitrate leaching of nitrogen fertilizer from global meta-analysis. Sci. Total Environ. 657, 96-102. https://doi.org/10.1016/j.scitotenv.2018.12.029 (2019).

10. Smith, V. H. In Cultural Eutrophication of Inland, Estuarine, and Coastal Waters (eds Pace, M. L. \& Groffman, P. M.) 7-49 (Springer, New York, 1998)

11. Carpenter, S. R. et al. Nonpoint pollution of surface waters with phosphorus and nitrogen. Ecol. Appl. 8, 559-568. https://doi. org/10.2307/2641247 (1998).

12. Wu, Y. \& Liu, S. Modeling of land use and reservoir effects on nonpoint source pollution in a highly agricultural basin. J. Environ. Monit. 14, 2350-2361. https://doi.org/10.1039/C2EM30278K (2012).

13. Shi, M., Xiao, W. H. \& Wang, C. M. The research progress of agricultural non-point source pollution in the black soil area of Northeast China. Adv. Mater. Res. 1010-1012, 711-716. https://doi.org/10.4028/www.scientific.net/AMR.1010-1012.711 (2014).

14. $\mathrm{Wu}, \mathrm{Y}$. \& Chen, J. Investigating the effects of point source and nonpoint source pollution on the water quality of the East River (Dongjiang) in South China. Ecol. Indic. 32, 294-304. https://doi.org/10.1016/j.ecolind.2013.04.002 (2013).

15. Walmsley, D. C. et al. Reduced nitrate leaching from an Irish cropland soil under non-inversion tillage with cover cropping greatly outweighs increased dissolved organic nitrogen leaching. Agric. Ecosyst. Environ. 265, 340-349. https://doi.org/10.1016/j. agee.2018.06.031 (2018).

16. Brown, K., Duble, R. \& Thomas, J. Influence of management and season on fate of N applied to golf greens 1. Agron. J. 69, 667-671. https://doi.org/10.2134/agronj1977.00021962006900040036x (1977).

17. Jamali, H., Quayle, W. C. \& Baldock, J. Reducing nitrous oxide emissions and nitrogen leaching losses from irrigated arable cropping in Australia through optimized irrigation scheduling. Agric. For. Meteorol. 208, 32-39. https://doi.org/10.1016/j.agrfo rmet.2015.04.010 (2015).

18. Wang, W., Wu, X., Yin, C. \& Xie, X. Nutrition loss through surface runoff from slope lands and its implications for agricultural management. Agric. Water Manag. 212, 226-231. https://doi.org/10.1016/j.agwat.2018.09.007 (2019).

19. Adimassu, Z., Alemu, G. \& Tamene, L. Effects of tillage and crop residue management on runoff, soil loss and crop yield in the humid highlands of Ethiopia. Agric. Syst. 168, 11-18. https://doi.org/10.1016/j.agsy.2018.10.007 (2019).

20. Wang, S.-C. et al. The efficiency of long-term straw return to sequester organic carbon in Northeast China's cropland. J. Integr. Agric. 17, 436-448. https://doi.org/10.1016/S2095-3119(17)61739-8 (2018).

21. Sojka, R., Bjorneberg, D., Entry, J., Lentz, R. \& Orts, W. Polyacrylamide in agriculture and environmental land management. Adv. Agron. 92, 75-162. https://doi.org/10.1016/S0065-2113(04)92002-0 (2007).

22. Yang, X., Finne-Wistrand, A. \& Hakkarainen, M. Improved dispersion of grafted starch granules leads to lower water resistance for starch-g-PLA/PLA composites. Compos. Sci. Technol. 86, 149-156. https://doi.org/10.1016/j.compscitech.2013.07.013 (2013).

23. Witono, J. R., Noordergraaf, I., Heeres, H. \& Janssen, L. Water absorption, retention and the swelling characteristics of cassava starch grafted with polyacrylic acid. Carbohydr. Polym. 103, 325-332. https://doi.org/10.1016/j.carbpol.2013.12.056 (2014).

24. Chaudhuri, S. D., Mandal, A., Dey, A. \& Chakrabarty, D. Tuning the swelling and rheological attributes of bentonite clay modified starch grafted polyacrylic acid based hydrogel. Appl. Clay Sci. 185, 105405. https://doi.org/10.1016/j.clay.2019.105405 (2020).

25. Ghorbani, M., Asadi, H. \& Abrishamkesh, S. Effects of rice husk biochar on selected soil properties and nitrate leaching in loamy sand and clay soil. Int. Soil Water Conserv. Res. 7, 258-265. https://doi.org/10.1016/j.iswcr.2019.05.005 (2019).

26. Liu, X. et al. Biosorption of copper ions from aqueous solution using rape straw powders: optimization, equilibrium and kinetic studies. Ecotoxico. Environ. Saf. 150, 251-259. https://doi.org/10.1016/j.ecoenv.2017.12.042 (2018).

27. Yu, W., Yujun, W., Zhonglei, X., Yujia, S. \& Fangning, G. Sorption behavior of aluminum in black and albic soils and its response to environmental conditions. Soil Sediment Contam. 28, 485-501. https://doi.org/10.1080/15320383.2019.1623169 (2019).

28. Feng, Y. et al. Carboxylic acid functionalized sesame straw: a sustainable cost-effective bioadsorbent with superior dye adsorption capacity. Bioresour. Technol. 238, 675-683. https://doi.org/10.1016/j.biortech.2017.04.066 (2017).

29. Haroon, M. et al. Synthesis and characterization of carboxymethyl starch-g-polyacrylic acids and their properties as adsorbents for ammonia and phenol. Int. J. Biol. Macromol. 138, 349-358. https://doi.org/10.1016/j.ijbiomac.2019.07.046 (2019).

30. Bao, Y., Zhou, Q. \& Wang, Y. Adsorption characteristics of tetracycline by two soils: assessing role of soil organic matter. Soil Res. 47, 286-295. https://doi.org/10.1071/SR08112 (2009).

31. Chen, P. et al. Recovery efficiency and loss of $15 \mathrm{~N}$-labelled urea in a rice-soil system under water saving irrigation in the Songnen Plain of Northeast China. Agric. Water Manag. 222, 139-153. https://doi.org/10.1016/j.agwat.2019.04.026 (2019).

32. Paz-Ferreiro, J., Marinho, M. D. A., de Abreu, C. A. \& Vidal-Vázquez, E. Soil texture effects on multifractal behaviour of nitrogen adsorption and desorption isotherms. Biosyst. Eng. 168, 121-132. https://doi.org/10.1016/j.biosystemseng.2018.01.009 (2018).

33. Jouquet, P., Huchet, G., Bottinelli, N., Thu, T. D. \& Duc, T. T. Does the influence of earthworms on water infiltration, nitrogen leaching and soil respiration depend on the initial soil bulk density? A mesocosm experiment with the endogeic species Metaphire posthuma. Biol. Fertil. Soils 48, 561-567. https://doi.org/10.1007/s00374-011-0652-3 (2012).

34. Wang, X. Management of agricultural nonpoint source pollution in China: current status and challenges. Water Sci. Technol. 53, 1-9. https://doi.org/10.2166/wst.2006.033 (2006).

35. Hui, L. et al. Chemical fertilizers could be completely replaced by manure to maintain high maize yield and soil organic carbon (SOC) when SOC reaches a threshold in the Northeast China Plain. J. Integr. Agric. 16, 937-946. https://doi.org/10.1016/S2095 -3119(16)61559-9 (2017).

36. Shan, L. et al. Spatial variability of soil bulk density and its controlling factors in an agricultural intensive area of Chengdu Plain Southwest China. J. Integr. Agric, 18, 290-300 (2019).

\section{Acknowledgements}

This work was supported by the National Key Research and Development Program of China (2016YFD0300803), the Natural Science Foundation of Jilin Province, China (20180101086JC), and the Science and Technology Development Plan Project of Jilin Province(20200503004SF). 


\section{Author contributions}

Y.W. and H.G. have deigned the study. Y.W., H.G. and Z.X collected the sample and performed the experimental assay. L.Z., X.M. and C.P. performed the computational analysis, Y.W. and H.G. drafed the manuscript. Y.W. supervised the study and revised the manuscript.

\section{Competing interests}

The authors declare no competing interests.

\section{Additional information}

Correspondence and requests for materials should be addressed to Z.X. or L.Z.

Reprints and permissions information is available at www.nature.com/reprints.

Publisher's note Springer Nature remains neutral with regard to jurisdictional claims in published maps and institutional affiliations.

(c) (i) Open Access This article is licensed under a Creative Commons Attribution 4.0 International License, which permits use, sharing, adaptation, distribution and reproduction in any medium or format, as long as you give appropriate credit to the original author(s) and the source, provide a link to the Creative Commons licence, and indicate if changes were made. The images or other third party material in this article are included in the article's Creative Commons licence, unless indicated otherwise in a credit line to the material. If material is not included in the article's Creative Commons licence and your intended use is not permitted by statutory regulation or exceeds the permitted use, you will need to obtain permission directly from the copyright holder. To view a copy of this licence, visit http://creativecommons.org/licenses/by/4.0/.

(C) The Author(s) 2020 